\title{
Endogenous Heparin-Like Substances May Cause Coagulopathy in a Patient with Severe Postpartum Hemorrhage
}

\author{
Shichun Wang Chao Qi Zhicheng Liu Ting Xu Chunyan Yao \\ Department of Blood Transfusion, Southwest Hospital, Third Military Medical University (Army Medical University), \\ Chongqing, China
}

\section{Keywords}

Postpartum hemorrhage $\cdot$ Disseminated intravascular coagulation · Endogenous heparin · Thromboelastography · Coagulopathy

\begin{abstract}
Introduction: Postpartum hemorrhage (PPH) is associated with maternal morbidity and mortality. Accurate diagnosis of the cause of puerperal hemorrhage is as important as treatment strategies for resuscitation. We report a case of coagulation disorder caused by endogenous heparin-like substances in a PPH patient. Case Presentation: A 30-yearold woman with no medical history of bleeding disorders suffered intractable hemorrhage following spontaneous delivery in a local hospital. The patient was transferred to the department of obstetrics of a superior hospital. On arrival, the patient was found to have severe hemorrhagic anemia, hemorrhagic shock, and disseminated intravascular coagulation. Active treatments were performed, but the patient continued bleeding. Laboratory testing, performed during early treatment, revealed that all coagulation factors were below normal. The differences between CK-TEG R-time (reaction time in citrated kaolin thromboelastography assay) and CKH-TEG R-time (reaction time in citrated kaolin with heparinase thromboelastography assay) suggested the presence of heparin activity. However, the patient's family denied heparin use prior to presentation. Thus, we deduced
\end{abstract}

that endogenous heparin-like substances were the main cause of the coagulopathy. After receiving treatment with protamine, the patient stopped bleeding. Meanwhile, all coagulation parameters and the TEG assay results improved. Conclusions: In this case report, TEG assay suggested the presence of heparin activity in a PPH patient, and treatment also highlighted the importance of analyzing different parameters in TEG.

C 2019 S. Karger AG, Basel

\section{Introduction}

Postpartum hemorrhage (PPH) is a leading cause of maternal mortality worldwide. The four main causes of $\mathrm{PPH}$ are uterine atony, trauma to the birth canal, retained placental tissue, and impaired hemostasis. However, 20\% of PPH occurs in women with no known risk factors [1]. An accurate diagnosis of the causes of $\mathrm{PPH}$ is important and urgent, since treatment strategies differ depending on the cause.

\section{Case Presentation}

A 30-year-old woman, without any history of coagulation disorders, delivered a healthy infant at 21:40, March 13, 2016 (40 5/7 weeks of gestation), via vaginal birth at a local hospital. Following recognition of uterine atony, retained placenta, and brisk blood 


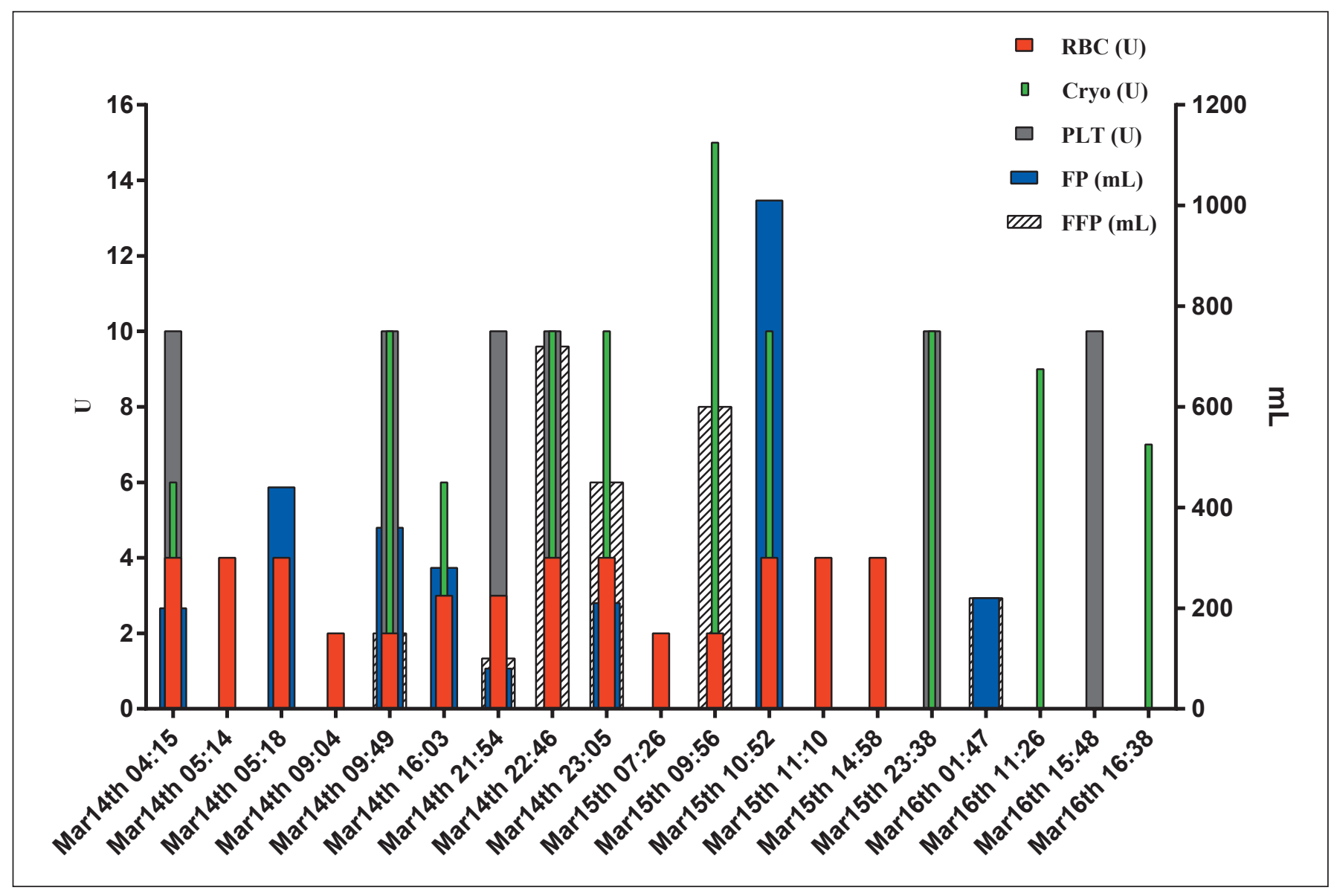

Fig. 1. Blood transfusion units during the entire treatment. RBC, red blood cells; Cryo, cryoprecipitate; PLT, platelets; FP, frozen plasma; FFP, fresh frozen plasma.

flow, urgent treatments including bimanual compression of the uterus and use of uterotonic medications were performed. However, the amount of bleeding continued to increase, and the patient was transferred to the department of obstetrics of a superior hospital.

The patient was diagnosed with severe hemorrhagic anemia, hemorrhagic shock, and disseminated intravascular coagulation according to the laboratory tests performed at the superior hospital (03:30, March 14, 2016). After vaginal inspection, multiple superficial mucosal vaginal lacerations and a large hematoma of the cervix were found, and the total vaginal blood loss was about 600 $\mathrm{mL}$. Hemostasis and suture with interrupted stitches by absorbable 2-0 vicryl were performed immediately; however, hemostasis was not achieved. Under ultrasonographic guidance, retained placental fragments and blood clots were discovered, and a Cook Cervical Ripening Balloon filled with $360 \mathrm{~mL}$ of normal saline was applied to prevent hematoma. Nevertheless, the bleeding still did not stop. After an exploratory laparotomy and total hysterectomy, no further bleeding was observed. During treatment, red blood cells $(12 \mathrm{U})$, platelets $(10 \mathrm{U})$, plasma $(640 \mathrm{~mL})$, and cryoprecipitates (6 U) were transfused (from 04:15 to 05:18, March 14; Fig. 1).

Twenty hours after admission (23:30, March 14), the patient began hemorrhaging again. Exploratory laparotomy revealed massive hemoperitoneum (about 2,500 mL) with active bleeding. Bilateral internal iliac artery ligation was performed, and the bleeding was temporarily stopped. Massive transfusion continued (red blood cells [8 U], platelets [10 U], plasma [1,385 mL], cryoprecip- itates [20 U], and prothrombin complex concentrates [600 IU]) from 23:05, March 14 to 01:30, March 15 (Fig. 1).

Thirty-one hours and $30 \mathrm{~min}$ later (11:00, March 15), the patient underwent a third operation because of recurrent active bleeding. Similarly, exploratory laparotomy revealed massive hemoperitoneum (about 2,500 mL). Hemostasis and suturing were performed. Blood component transfusion (red blood cells [12 U], plasma $[1,510 \mathrm{~mL}]$, cryoprecipitates $[40 \mathrm{U}]$, prothrombin complex concentrates $[1,200 \mathrm{IU}]$, and coagulation factors [40 mL]) were given (Fig. 1).

Hemostasis was monitored during the entire treatment. Laboratory testing revealed elevated or prolonged coagulation parameters, including activated partial thromboplastin time (aPTT), thrombin time (TT), D-dimer, prothrombin time (PT), and fibrin (-ogen) degradation products (FDP) (05:49, March 14; Table 1). All coagulation factor levels, including fibrinogen (Fib), factor II (F II), factor V (F V), factor VII (F VII), factor VIII (F VIII), factor IX (F IX), factor X (F X), factor XI (F XI), and factor XII (F XII), were below normal (13:29, March 14; Table 2).

To monitor coagulation and guide transfusion strategy, thromboelastography (TEG) assays were performed during the entire treatment. Similar results were obtained by the TEG assay (an assay which measures fibrin clot strength); almost all parameters in the TEG assay (e.g., R, K, and MA) were abnormal (Tables 3 and 4). The CK-TEG R-time (reaction time in citrated kaolin TEG assay) was $33.4 \mathrm{~min}$, and the CKH-TEG R-time (reaction time in citrated kaolin with heparinase TEG assay) was 17.2 min on March 
Table 1. Standard laboratory hemostasis testing

\begin{tabular}{|c|c|c|c|c|c|c|c|}
\hline Testing time & $\begin{array}{l}\text { Fib } \\
(1.8-3.7 \mathrm{~g} / \mathrm{L})\end{array}$ & $\begin{array}{l}\text { aPTT-Act } \\
(21.4-32.7 \mathrm{~s})\end{array}$ & $\begin{array}{l}\text { aPTT ratio } \\
(0.82-1.25)\end{array}$ & $\begin{array}{l}\text { PT } \\
(9.8-13.7 \mathrm{~s})\end{array}$ & $\begin{array}{l}\text { TT } \\
(14-21 \mathrm{~s})\end{array}$ & $\begin{array}{l}\text { FDP } \\
(0-5 \mathrm{mg} / \mathrm{L})\end{array}$ & $\begin{array}{l}\mathrm{D}-\mathrm{Di} \\
(0-0.55 \mathrm{mg} / \mathrm{L})\end{array}$ \\
\hline March 14, 05:49 & 0.52 & Over limit & 4.63 & 53.3 & Over limit & 167.3 & - \\
\hline March $14,06: 59$ & 0.9 & 110.2 & 4.16 & 19.6 & 38.2 & 44.2 & Over limit \\
\hline March $14,13: 24$ & 0.98 & 132.5 & 2.75 & 30.1 & 55.6 & - & 16.84 \\
\hline March 14, 22:40 & 1.32 & 165.7 & 6.25 & 19.1 & Over limit & - & 2.37 \\
\hline March 15, 03:41 & 3.27 & Over limit & Over limit & 15.9 & Over limit & 4.3 & 1.28 \\
\hline March 15, 09:21 & 3.21 & Over limit & - & 16.7 & Over limit & 4.5 & 2.2 \\
\hline March $15,17: 40$ & 2.2 & 48.2 & 1.82 & 12 & Over limit & 3.7 & 0.99 \\
\hline March 15, 22:12 & 2.44 & 48.9 & 1.85 & 12.3 & Over limit & 4.3 & 1.04 \\
\hline March 16, 09:09 & 3.22 & 116.20 & 4.44 & 13.8 & 51.60 & - & 1.65 \\
\hline March 16, 11:44 & 3.05 & 159.1 & 6.07 & 11.4 & Over limit & - & 1.65 \\
\hline March 16, 11:48 & N/A & 41.4 & 1 & 11.4 & 48.5 & - & - \\
\hline March 17, 00:19 & 2.78 & 37.1 & 1.4 & 9.2 & 29.4 & - & 1.59 \\
\hline March 17, 06:51 & 2.66 & 36 & 1.36 & 11 & 20 & 9.4 & 1.75 \\
\hline March 18, 09:51 & 2.72 & 39 & 1.49 & 11.6 & 17 & 42.5 & 15.64 \\
\hline March 19, 09:42 & 2.09 & 38.4 & 1.47 & 11.8 & 18.3 & 100.3 & 40.53 \\
\hline March 20, 09:44 & 1.7 & 37.5 & 1.43 & 11.4 & 17.8 & 100.3 & 31.15 \\
\hline March 21, 09:11 & 1.74 & 36.4 & 1.39 & 12.3 & 18.7 & 45.1 & 20.9 \\
\hline March 22, 09:12 & 1.72 & 38.2 & 1.46 & 12.3 & 18 & 26.3 & 10.11 \\
\hline March 23, 06:14 & 1.9 & 32.3 & 1.22 & 12.8 & 22.4 & 23.5 & 3.56 \\
\hline
\end{tabular}

Table 2. Coagulation factor assays

\begin{tabular}{lllllllll}
\hline Testing time & $\begin{array}{l}\text { F II } \\
(70-120 \%)\end{array}$ & $\begin{array}{l}\text { F V } \\
(70-120 \%)\end{array}$ & $\begin{array}{l}\text { F VII } \\
(70-120 \%)\end{array}$ & $\begin{array}{l}\text { F VIII } \\
(70-150 \%)\end{array}$ & $\begin{array}{l}\text { F IX } \\
(70-120 \%)\end{array}$ & $\begin{array}{l}\text { F X } \\
(70-120 \%)\end{array}$ & $\begin{array}{l}\text { F XI } \\
(70-120 \%)\end{array}$ & $\begin{array}{l}\text { F XII } \\
(70-150 \%)\end{array}$ \\
\hline March 14, 13:29 & 27.3 & 7.5 & 39.7 & 54.5 & 48.6 & 27.4 & 29.7 & 23.3 \\
March 14, 21:43 & 34.5 & 17.9 & 40.7 & 61.8 & 43.6 & 48 & 21.3 & 16.7 \\
March 15, 14:13 & 84.6 & 47.1 & 75.9 & 101.9 & 37.3 & 78.6 & 18.3 & 29.1 \\
March 16, 11:44 & 94.1 & 51.4 & 81.6 & 122.5 & 72.3 & 72.6 & 37.2 & 34.8 \\
March 17, 11:21 & 105 & 56.6 & 142.8 & 135.9 & 111 & 79.8 & 77.7 & 37.6 \\
March 18, 13:13 & 81 & 70.1 & 109 & 135.6 & 110.6 & 88.1 & 53.5 & 36.3 \\
March 19, 11:24 & 71.9 & 72.3 & 89.2 & 205.6 & 60.3 & 132.6 & 58.3 & 49 \\
March 21, 12:06 & 72.1 & 94.6 & 115.1 & 142.1 & 92.5 & 151.3 & 42.2 & 37.4 \\
March 21, 12:06 & 78.5 & 83 & 125.4 & 94.5 & 111.5 & 158.3 & 47.2 & 37.1 \\
March 22, 11:11 & 67.1 & 86.3 & 76.3 & 183.9 & 64 & 43 & 48.7 & 32.6 \\
\hline
\end{tabular}

14. On March 15, the CK-TEG R-time was over the limit, and the differences between CK-TEG R-time and CKH-TEG R-time were too large to be estimated (Fig. 2). These results suggested the presence of heparin effect [2]. The patient's family denied heparin use in the pretreatment procedure. Thus, endogenous heparin-like substances were deduced to be the main reason for the coagulation disorders.

To neutralize heparin effects and restore thrombin activity, 30 mg protamine was used at 8:50 on March 16. Then, activated clotting time (ACT) assay was performed to observe whether heparinase effects were eliminated. The ACT shortened from $356 \mathrm{~s}$ (23:00, March 15) to 206 s (10:02, March 16) (Fig. 3). Additionally, the coagulation parameters including aPTT, TT (Table 1), coagulation factors (Table 2), and the results of the TEG assay (Fig. 2, Tables 3 and 4) also improved after protamine treatment. Thus, another $30 \mathrm{mg}$ protamine was used for the complete correction and resolution of bleeding. On March 24, the patient was discharged from the hospital after recovery.

\section{Discussion}

Uterine atony seemed to be the main cause for this patient's initial hemorrhage, consistent with previous reports, in which atony accounted for $80 \%$ of the hemorrhages [1]. PPH caused by endogenous heparin-like substances has not been reported previously. However, there have been similar reports in other diseases [3-5]. Many experts recommend monitoring hemostasis with either PT/aPTT and Clauss fibrinogen or thromboelastometry during $\mathrm{PPH}$ [6]. As a point of care assay, TEG can provide measurements of coagulation and fibrinolysis in $30 \mathrm{~min}$. Berlot et al. [7] and Zambruni et al. [8] both suggested that TEG is the best method to diagnose endogenous heparin-like substances. The difference between CK-TEG Rtime and CKH-TEG R-time is associated with heparin 
Table 3. Citrated kaolin TEG assay results

\begin{tabular}{llllll}
\hline Testing time & R $(5-10 \mathrm{~min})$ & $\mathrm{K}(1-3 \mathrm{~min})$ & Angle $(55-78 \mathrm{deg})$ & MA $(50-70 \mathrm{~min})$ & $\mathrm{CI}(-3-+3)$ \\
\hline March 14, 6:44 & 16.8 & 8.8 & 24.3 & 36.1 & -15.8 \\
March 14, 14:41 & 33.4 & 14.3 & 12.7 & 32.7 & -30 \\
March 14, 23:44 & 20.6 & 6.8 & 28.6 & 46.1 & -15.9 \\
March 15, 8:17 & Over limit & Over limit & Over limit & Over limit & Over limit \\
March 15, 9:55 & Over limit & Over limit & Over limit & Over limit & Over limit \\
March 15, 11:10 & Over limit & Over limit & Over limit & Over limit & Over limit \\
March 15, 14:18 & 108.3 & Over limit & 0.6 & 2.3 & Over limit \\
March 15, 15:10 & 10.1 & 2.5 & 56.5 & 52.2 & -4.6 \\
March 15, 22:14 & 20.2 & 9.6 & 19.3 & 32.5 & -19.2 \\
March 16, 8:43 & Over limit & Over limit & Over limit & Over limit & Over limit \\
March 16, 15:25 & 11.7 & 5 & 21.3 & 50.2 & -9.5 \\
March 16, 22:49 & 9.6 & 1.9 & 60.7 & 57.4 & -3.1 \\
March 17, 8:54 & 9.5 & 2.2 & 59.5 & 59 & -3.1 \\
March 17, 16:16 & 9.4 & 1.6 & 66.8 & 63.5 & -1.7 \\
March 18, 9:34 & 6.8 & 2.2 & 59.5 & 57.8 & -1.4 \\
March 19, 9:04 & 6.9 & 3.5 & 47 & 53.4 & -3.5 \\
March 20, 8:16 & 2.5 & 1.2 & 73.2 & 67.2 & 3.9 \\
March 21, 9:04 & 5.8 & 2.2 & 60.9 & 59.2 & -0.5 \\
\hline
\end{tabular}

Table 4. Citrated kaolin TEG with heparinase assay results

\begin{tabular}{lllllr}
\hline Testing time & $\begin{array}{l}\mathrm{R} \\
(5-10 \mathrm{~min})\end{array}$ & $\begin{array}{l}\mathrm{K} \\
(1-3 \mathrm{~min})\end{array}$ & $\begin{array}{l}\text { Angle } \\
(55-78 \mathrm{deg})\end{array}$ & $\begin{array}{l}\text { MA } \\
(50-70 \mathrm{~min})\end{array}$ & $\begin{array}{l}\text { CI } \\
(-3-+3)\end{array}$ \\
\hline March 14, 9:57 & 14.3 & 12.8 & 19.7 & 30.2 & 14.3 \\
March 14, 10:00 & 9.6 & 8.6 & 27.8 & 38.4 & 9.6 \\
March 14, 14:41 & 17.2 & 4.6 & 39.6 & 43.8 & 17.2 \\
March 14, 23:44 & 11.8 & 6.8 & 31 & 37.4 & 11.8 \\
March 15, 10:18 & 17.1 & 4 & 45.1 & 54.9 & 17.1 \\
March 15, 14:19 & 13.7 & 3.4 & 48.8 & 52.1 & 13.7 \\
March 15, 15:11 & 10 & 2.6 & 57.3 & 46.6 & 10 \\
March 15, 17:55 & 10.1 & 2.7 & 59.7 & 39.6 & 10.1 \\
March 15, 22.13 & 10.1 & 2.4 & 60.2 & 46.4 & 10.1 \\
March 16, 8:42 & 13.8 & 8.6 & 22.9 & 36.8 & 13.8 \\
March 16, 12:53 & 10.2 & 3.7 & 47.3 & 43.4 & 10.2 \\
March 16, 22:48 & 7.8 & 2.1 & 62 & 47.7 & 7.8 \\
March 17, 8:55 & 9.2 & 2.1 & 60.7 & 55.5 & 9.2 \\
March 17, 16:26 & 8.2 & 2 & 62.3 & 54.9 & 8.2 \\
March 18, 9:34 & 7.5 & 2.3 & 59.7 & 54.2 & 7.5 \\
March 21, 9:04 & 5.9 & 1.9 & 63.6 & 51.4 & 5.9 \\
\hline
\end{tabular}

effects, although the difference cannot give a quantitative level of heparin.

In this case, all doctors initially focused on treatment strategies for resuscitation. After all obvious reasons for $\mathrm{PPH}$ were treated successfully with surgical treatments and massive transfusion protocol, the patient still presented with persistent hemorrhage. At this time, the doctors reviewed all laboratory results and noticed the abnormal TEG results. CK-TEG R-time was $33.4 \mathrm{~min}$, $\mathrm{CKH}$ TEG R-time was 17.2 min at 14:41 on March 14, and the differences between CK-TEG R-time and CKH-TEG Rtime were much larger during the entire day of March 15
(Fig. 2). Thus, an inferential diagnosis of heparin effect was made. However, the patient denied heparin use prior to presentation, and there was no administration of heparin in her admissions records. Thus, we speculated that the heparin effect might be from endogenous heparinlike substances. Durila et al. [5] suggested that for bleeding patients with an endogenous heparinoid effect who were not responding to standard therapy, protamine sulphate administration should be considered based on the TEG results. For this patient, $30 \mathrm{mg}$ protamine was used to neutralize the heparin effects, and the ACT assay was performed to observe whether protamine was indeed an 


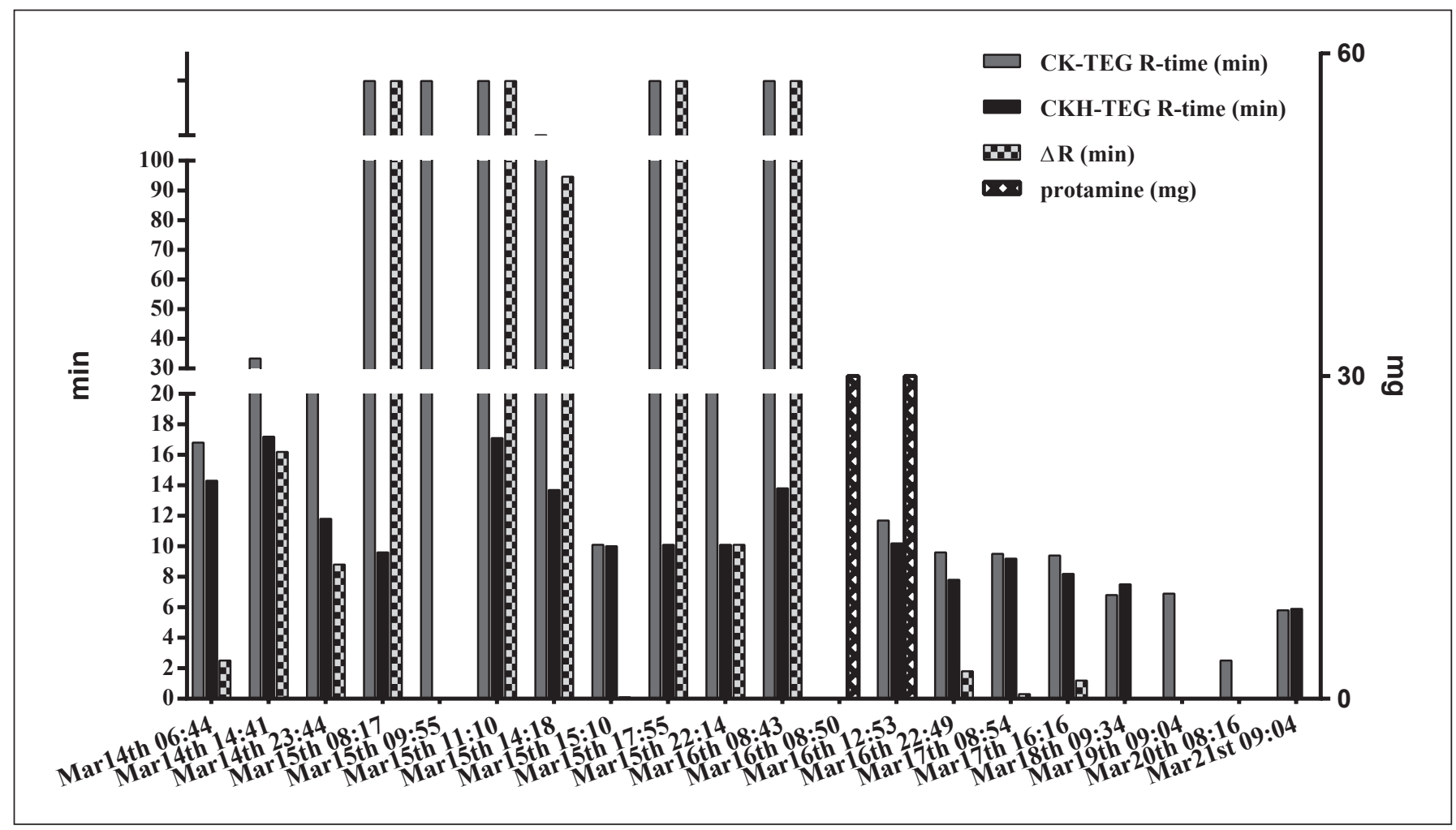

Fig. 2. Citrated kaolin TEG (with and without heparinase) assay result and the protamine dose during the entire treatment. R, reaction time, defined as the time from the start of the test to the onset of fibrin formation; CK-TEG R-time, reaction time in citrated kaolin TEG assay; CKH-TEG R-time, reaction time in citrated kaolin with heparinase TEG assay; $\Delta \mathrm{R}$, the difference between CK-TEG R-time and CKH-TEG R-time.

appropriate treatment to endogenous heparin-like substances (Fig. 3). The administration of protamine stopped the bleeding successfully, further confirming our deduction.

Bulanov et al. [9] considered that endogenous heparin-like substances were a possible cause of non-surgical bleeding; this helped to explain the heparin effect in the absence of an exogenous application. At present, there is no gold standard for diagnosing endogenous heparin-like substances, except for high-performance liquid chromatography (HPLC); however, HPLC is not normally used in clinical settings. In this case, we did not measure the level of the endogenous heparin-like substances, but we deduced that they were present from the clinical manifestations of the patient. Heparan sulphate is a highly sulphated endogenous heparinoid which normally constitutes a small proportion of the plasma glycosaminoglycans (GAGs) [10]. In several abnormal bleeding reports, high values of heparan sulphate have been found [11-13]. To measure the concentration of endogenous heparinoid substances, McKee et al. [14] measured the concentration of heparan sulphate in blood using a competitive binding assay. They concluded that the normal range of heparan sulphate in patients with no recent bleed should be $<600$

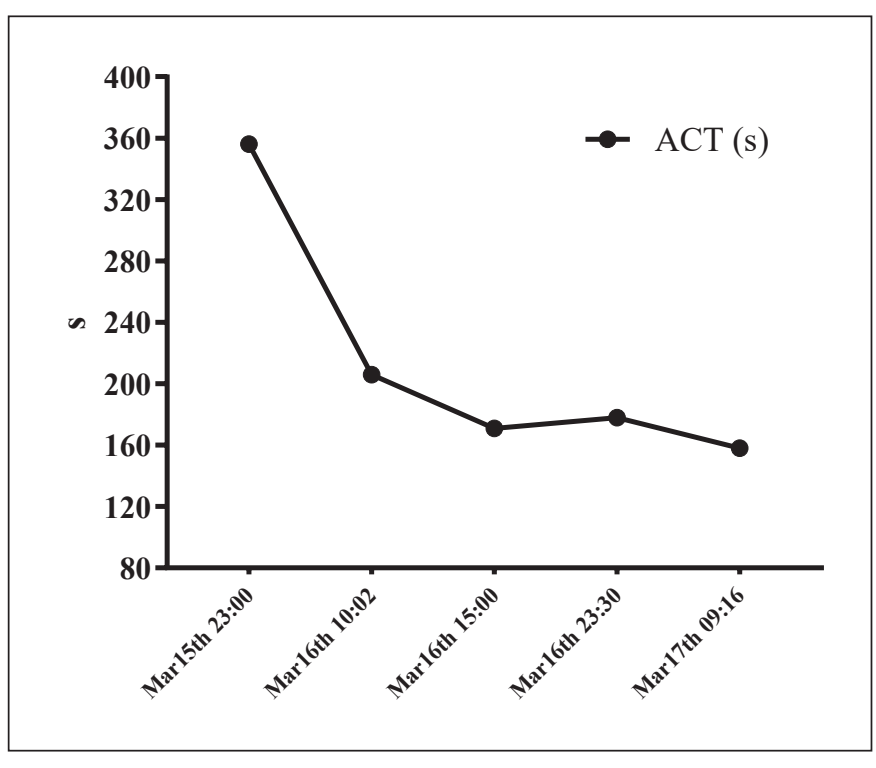

Fig. 3. The patient's ACT assay before and after protamine administration. 
$\mathrm{ng} / \mathrm{mL}$, while the median value increased to $1,700 \mathrm{ng} / \mathrm{mL}$ when patients had experienced a bleed within 28 days.

Endogenous heparinoids, including heparan sulphate, heparin, and dermatan sulphate, when released into the bloodstream can cause severe bleeding [15]. Endogenous heparinoids are GAGs, complex macromolecules consisting of long chains of modified sugars that are present in the extracellular matrix and on the membrane surfaces of cells. The normal concentration of GAGs in the plasma is low; however, high levels of GAGs can increase the risk of bleeding [16]. Mechanisms leading to increased endogenous heparinoids are multifactorial, and include (i) failure of the liver to clear the circulating GAGs during acute liver failure, (ii) neutrophil-mediated injury of the hepatocytes that can release heparan sulphate, and (iii) the direct release of GAGs from the endothelial surface and the mast cells during sepsis and systemic inflammation response syndrome, and that was strongly associated with thromboelastographic signs of coagulopathy [17-19]. In this case, we propose that protamine administration eliminated the heparinase effects, the patient's vascular endothelium and other cells were restored, and release of heparin-like substances was stopped. That may be the mechanism by which the patient stopped bleeding.

Laboratory tests for hemorrhage, including hemoglobin, platelet count, aPTT, PT, international normalized ratio, and fibrinogen, have several general and practical limitations. These limitations include delays in test results, lack of real-time monitoring, and inability to assess hemostatic functionality (including clot strength and platelet dysfunction) [20]. In this case, we discovered elevated or prolonged aPTT, TT, D-dimer, PT, and FDP, and low levels of coagulation factors, including Fib, F II, F V, F VII, F VIII, F IX, F X, F XI, and F XII. Based on these results, massive transfusion protocol was performed three times for correction of coagulation. Comparison of CK-TEG versus CKH-TEG can help distinguish between heparin activity or coagulation factor deficiency as a cause of bleeding complications and can provide a rational approach to the treatment of bleeding [3]. TEG has been proven superior to conventional laboratory assays in many circumstances and has been validated and used in obstetric hemorrhage [21-23]. The TEG results have been incorporated into various hemostasis algorithms to guide transfusion therapy [24].

However, several limitations of this case are worth mentioning. First, functional fibrinogen TEG test and tissue factor activated test data are missing, because these two tests were not run in our laboratory. Reporting only the differences between CK-TEG R-time and CKH-TEG R-time uses only a small potential of viscoelastic testing in bleeding management, particularly in PPH. Second, we tested the TEG test only once for each sample, thus the reproducibility of the TEG test could not be evaluated.

\section{Conclusions}

In conclusion, coagulation monitoring is a key process for $\mathrm{PPH}$ resuscitation. Coagulopathy can be caused either by coagulation factor deficiencies or by released exogenous heparin (heparinoids). In this case, comparison of CK-TEG versus CKH-TEG may have helped detect the heparin effect of endogenous heparin-like substances. We also highlight the importance of parameters analysis of TEG assay for treating PPH.

\section{Acknowledgement}

We gratefully acknowledge the patient and her family members. We thank all obstetricians (obstetrics department of the First Affiliated Hospital of the Third Military Medical University) for their contribution in treating the patient.

\section{Statement of Ethics}

Written informed consent was obtained from the patient.

\section{Disclosure Statement}

The authors declare that they have no conflicts of interest relevant to the present study.

\section{Funding Sources}

This project was in part supported by the National Natural Science Foundation of China (NSFC 81700180) and the youth training plan of the Southwest Hospital (SWH2018QNKJ-22).

\section{Author Contributions}

Shichun Wang and Chunyan Yao designed the research, interpreted the data, and wrote the manuscript. Chao Qi and Zhicheng Liu performed the experiments, collected and interpreted the data, and participated in manuscript preparation. Ting Xu interpreted the data and participated in manuscript preparation. All authors critically revised the manuscript and approved the final version.

\section{References}

1 Evensen A, Anderson JM, Fontaine P. Postpartum Hemorrhage: prevention and Treatment. Am Fam Physician. 2017 Apr;95(7): 442-9.

2 Galeone A, Rotunno C, Guida P, Bisceglie A, Rubino G, Schinosa LL, et al. Monitoring incomplete heparin reversal and heparin rebound after cardiac surgery. J Cardiothorac Vasc Anesth. 2013 Oct;27(5):853-8. 
3 Kettner SC, Gonano C, Seebach F, Sitzwohl C, Acimovic S, Stark J, et al. Endogenous heparin-like substances significantly impair coagulation in patients undergoing orthotopic liver transplantation. Anesth Analg. 1998 Apr; 86(4):691-5.

4 Tefferi A, Nichols WL, Bowie EJ. Circulating heparin-like anticoagulants: report of five consecutive cases and a review. Am J Med. 1990 Feb;88(2):184-8.

5 Durila M, Pavlicek P, Hadacova I, Nahlovsky J, Janeckova D. Endogenous Heparinoids May Cause Bleeding in Mucor Infection and can be Detected by Nonactivated Thromboelastometry and Treated by Recombinant Activated Factor VII: A Case Report. Medicine (Baltimore). 2016 Feb;95(8):e2933.

6 Collins P, Abdul-Kadir R, Thachil J; Subcommittees on Women's Health Issues in Thrombosis and Haemostasis and on Disseminated Intravascular Coagulation. Management of coagulopathy associated with postpartum hemorrhage: guidance from the SSC of the ISTH. J Thromb Haemost. 2016 Jan; 14(1): 205-10.

7 Berlot G, Tartamella F, Bussani R, Vassallo MC, Gerebizza S. An uncommon cause of postoperative bleeding. Blood Coagul Fibrinolysis. 2011 Apr;22(3):231-3.

8 Zambruni A, Thalheimer U, Coppell J, Riddell A, Mancuso A, Leandro G, et al. Endogenous heparin-like activity detected by anti$\mathrm{Xa}$ assay in infected cirrhotic and non-cirrhotic patients. Scand J Gastroenterol. 2004 Sep;39(9):830-6.
9 Bulanov AI, Iatskov KV, Shulutko EM, Glukhova TE, Andreǐchenko SA. Endogenous heparin-like syndrome: analysis of clinical observations. Anesteziol Reanimatol. 2012 May-Jun;(3):51-4. Russian.

10 Teien AN. Heparin elimination in patients with liver cirrhosis. Thromb Haemost. 1977 Oct;38(3):701-6.

11 Calatroni A, Donnelly PV, Di Ferrante N. The glycosaminoglycans of human plasma. J Clin Invest. 1969 Feb;48(2):332-43.

12 Khoory MS, Nesheim ME, Bowie EJ, Mann KG. Circulating heparan sulfate proteoglycan anticoagulant from a patient with a plasma cell disorder. J Clin Invest. 1980 Mar;65(3): 666-74.

13 Palmer RN, Rick ME, Rick PD, Zeller JA, Gralnick HR. Circulating heparan sulfate anticoagulant in a patient with a fatal bleeding disorder. N Engl J Med. 1984 Jun;310(26): 1696-9.

14 McKee RF, Hodson S, Dawes J, Garden OJ, Carter DC. Plasma concentrations of endogenous heparinoids in portal hypertension. Gut. 1992 Nov;33(11):1549-52.

15 Wages DS, Staprans I, Hambleton J, Bass NM, Corash L. Structural characterization and functional effects of a circulating heparan sulfate in a patient with hepatocellular carcinoma. Am J Hematol. 1998 Aug;58(4):285-92.

16 Staprans I, Felts JM. Isolation and characterization of glycosaminoglycans in human plasma. J Clin Invest. 1985 Nov;76(5):1984-91.

17 Ranucci M, Baryshnikova E, Isgrò G, Carlucci C, Cotza M, Carboni G, et al. Heparin-like effect in postcardiotomy extracorporeal membrane oxygenation patients. Crit Care. 2014 Sep;18(5):504.
18 Ostrowski SR, Johansson PI. Endothelial glycocalyx degradation induces endogenous heparinization in patients with severe injury and early traumatic coagulopathy. J Trauma Acute Care Surg. 2012 Jul;73(1):60-6.

19 Halbgebauer R, Braun CK, Denk S, Mayer B, Cinelli P, Radermacher P, et al. Hemorrhagic shock drives glycocalyx, barrier and organ dysfunction early after polytrauma. J Crit Care. 2018 Apr;44:229-37.

20 de Lloyd L, Bovington R, Kaye A, Collis RE, Rayment R, Sanders J, et al. Standard haemostatic tests following major obstetric haemorrhage. Int J Obstet Anesth. 2011 Apr;20(2): 135-41.

21 Drumheller BC, Stein DM, Moore LJ, Rizoli SB, Cohen MJ. Thromboelastography and rotational thromboelastometry for the surgical intensivist: A narrative review. J Trauma Acute Care Surg. 2019 Apr;86(4):710-21.

22 Ekelund K, Hanke G, Stensballe J, Wikkelsøe A, Albrechtsen CK, Afshari A. Hemostatic resuscitation in postpartum hemorrhage - a supplement to surgery. Acta Obstet Gynecol Scand. 2015 Jul;94(7):680-92.

23 Noorman F, Hess JR. The contribution of the individual blood elements to the variability of thromboelastographic measures. Transfusion. 2018 Oct;58(10):2430-6.

24 Gurbel PA, Bliden KP, Tantry US, Monroe AL, Muresan AA, Brunner NE, et al. First report of the point-of-care TEG: A technical validation study of the TEG-6S system. Platelets. 2016 Nov;27(7):642-9. 